Vol. 12, $n^{\circ} 2 \mid 2008$

Varia

\title{
Entre résistance et acculturation. La peine capitale à Genève durant la période française (1798-1813)
}

Ludovic Maugué

\section{(2) OpenEdition \\ Journals}

Édition électronique

URL : https://journals.openedition.org/chs/357

DOI : $10.4000 /$ chs.357

ISSN : 1663-4837

Éditeur

Librairie Droz

Édition imprimée

Date de publication : 1 octobre 2008

Pagination : 33-57

ISBN : 978-2-600-01244-7

ISSN : $1422-0857$

Référence électronique

Ludovic Maugué, «Entre résistance et acculturation. La peine capitale à Genève durant la période française (1798-1813) ", Crime, Histoire \& Sociétés / Crime, History \& Societies [En ligne], Vol. 12, n² I 2008, mis en ligne le 01 octobre 2011, consulté le 22 mars 2022. URL : http:// journals.openedition.org/chs/357 ; DOl : https://doi.org/10.4000/chs.357

Ce document a été généré automatiquement le 22 mars 2022.

(c) Droz 


\title{
Entre résistance et acculturation. La peine capitale à Genève durant la période française $(1798-1813)^{1}$
}

\author{
Ludovic Maugué
}

1 Trop souvent considérée par l'historiographie comme une époque sombre et honteuse - synonyme de perte de souveraineté - la période durant laquelle Genève est rattachée à la France (1798-1813) a longtemps été appréhendée sous trois angles restrictifs : la souffrance et la crise, la résistance héroïque des Genevois, le départ des Français ${ }^{2}$. Or, les conséquences du Traité de réunion de la République de Genève à la République Française ne sauraient être réduites à ce constat dépréciatif ${ }^{3}$. Certes, le traumatisme engendré alors par ce rattachement forcé apparaît indéniable: indépendante et souveraine depuis l'adoption de la Réforme par le Conseil général des citoyens le 21 mai 1536, Genève est dès lors réduite au statut subalterne de chef-lieu d'un département (le Léman), qui, s'il occupe une superficie nettement supérieure à celle de la Genève patricienne, implique comme corollaire la minorisation des Genevois dans une entité territoriale à dominante catholique et rurale ${ }^{4}$.

2 Cependant, il s'avère que, au delà de cette perte de souveraineté - et de la crispation identitaire qu'elle engendre-, l'annexion à la France révolutionnaire, puis napoléonienne, représente un moment historique charnière pour ce qui a trait à l'étude de la justice en général et de la peine de mort en particulier, ceci aussi bien pour la Cité lémanique que pour la République française. Pendant quinze ans, à l'échelle d'un département, nous pouvons en effet observer de près la mise en œuvre d'un nouveau paradigme punitif, incarné par le Codepénal révolutionnaire de 1791 et prolongépar les dispositions légales successivement introduites sous le Directoire, le Consulat et l'Empire .

3 Au regard de cette unité de temps et de lieu, le département du Léman s'affirme comme un véritable laboratoire pour l'étude de la pénalité moderne, révélant non seulement le lien entre l'arbitraire de la justice d'Ancien Régime et le libéralisme pénal et politique qui prévaut à Genève au XIX ${ }^{e}$ siècle, mais illustrant surtout l'exportation d'un modèle 
de justice allogène dans une cité-État aux traditions juridiques et pénales séculaires. Or, la confrontation du modèle français de justice à la sensibilité et aux usages locaux ne manque pas de susciter autant l'adhésion que le rejet; dès lors, et c'est là l'un des principaux propos du présent article, la dualité entre résistance et acculturation se révèle patente pour l'ensemble des figures concernées par la justice pénale.

\section{L'énorme différence des temps}

4 La difficulté éprouvée par d'aucuns à saisir l'esprit d'une culture juridique nouvelle et d'en discerner positivement les avantages est manifeste chez bon nombre de membres $\mathrm{du}$ personnel judiciaire du département; mais elle l'est également pour la plupart des observateurs, contemporains ou postérieurs. Hormis Sismondi, dont l'appréciation du fonctionnement de la justice dans le département du Léman s'avère fort laudative ${ }^{6}$, les (très) rares commentateurs du XIX ${ }^{\mathrm{e}}$ siècle portent un regard négatif sur cette période et soulignent essentiellement la recrudescence des crimes alors observée :

À cette époque, le nombre des affaires criminelles fut assez considérable parce que la population du Département du Léman était de 180000 âmes et qu'alors il se commettait beaucoup de crimes, tellement que le gouvernement français fut obligé d'ordonner qu'aucune messagerie ou courrier ne se mit en route sans être accompagné par un certain nombre de militaires.

On peut juger de l'énorme différence des temps. M. Naville dans son ouvrage ${ }^{7}$ constate que de 1754 à 1789 , treize malfaiteurs seulement ont péri par la main du bourreau dans la juridiction genevoise de 95000 âmes; tandis que de 1799 à 1814 les Cours criminelles de Genève prononcèrent 56 condamnations à mort dont 34 reçurent leur exécution ${ }^{8}$.

5 Formulés dansune brochure manuscrite anonyme (env. 30 pages) attribuée à JeanÉlisée Massé 9 , ces propos évoquent « le nombre considérable » d'individus condamnés à la peine capitale durant l'époque française et laissent poindre - "énorme différence des temps »- une critique à peine voilée de cette période. En outre, si elle n'est pas explicitement mentionnée par l'auteur, la responsabilité de cette forte augmentation de la criminalité pourrait incomber aux populations résidentes des parties détachées des départements français voisins. Ce qui n'était que suggéré dans le relevé statistique de Massé prend la forme d'une diatribe passionnée dans la bouche de François Cougnard, qui considère, en 1826, que la propension au crime affichée par certains « individus pris chez nos voisins » constitue un argument irréfutable contre l'abolition de la peine capitale à Genève :

En abolissant la peine de mort, vous comprendrez, vous avouerez même que nous n'aurons pas travaillé absolument pour nous, mais bien plutôt pour quelques individus pris chez nos voisins ${ }^{10}$.

6 Si François Cougnard invoque la dangerosité de certaines populations des contrées limitrophes pour justifier le maintien de la peine de mort à Genève, il le fait avant tout en réponse à l'initiative du comte Jean-Jacques de Sellon (1782-1839) qui, le 21 janvier 1826, invite la rédaction du JournaldeGenève à publier un avis relatif à l'organisation d'un concours en faveur de la suppression absolue de la peine de mort ${ }^{11}$. Disposition notable, l'avis annonçant le concours encourage vivement les participants à développer leurs thèses au regard des spécificités de la Cité lémanique et en insistant sur le fait que l'existence dans cette ville « d'une prison pénitentiaire dans le principe panoptique de 
Bentham facilite la commutation de la peine de mort en prison perpétuelle pour les grands crimes $»^{12}$.

7 Bien qu'il n'y participe évidemment pas, Cougnard étaye en revanche son argumentation en fonction de certains points du concours; il souligne ainsi les particularités genevoises, coupables à ses yeux de rendre toute abolition impossible, et dénigre avec force ironie le «château de plaisance » que constituerait la prison semipanoptique conforme aux idées de Jeremy Bentham ${ }^{13}$ :

Avez-vous quelquefois parcouru les contrées qui nous avoisinent? Avez-vous visité celles qui par leur position sont le moins à même de se civiliser? Avez-vous vu quelques-unes de ces malheureuses bourgades où tout est reculé de quatre à cinq siècles, où le crime a trouvé tant de partisans? Si, comme moi, vous avez examiné la nature et le caractère de ces misérables; si, comme moi, vous les avez sondés dans leurs raisonnements et leurs usages, vous comprendrez sans peine qu'il n'est plus étonnant qu'il y ait eu là des hommes capables de commettre un assassinat; qu'il peut y en avoir encore qui, par leur ignorance et leur cupidité, ne verront qu'un attrait de plus dans l'abolition d'une peine qui ne se pratique plus chez nous, petit État d'où, comme ils savent fort bien le dire, il est facile d'échapper en une demiheure. Vous comprendrez que de tels hommes, invités par telle ou telle circonstance, ne verront rien de bien effrayant à l'aspect d'une prison qui a l'air d'un château de plaisance, qui l'est effectivement en comparaison de leurs huttes, et d'où il ne leur semble pas impossible de s'évader un jour, s'ils en ont l'envie ${ }^{14}$.

8 Certes, on pourrait objecter ici que le sombre tableau des "contrées qui nous avoisinent » dressé par Cougnard ne fait aucune référence explicite au département du Léman. Il est cependant indéniable que le jugement qu'il porte sur "ces misérables " est influencé par la crue de la criminalité réprimée durant l'époque française: non seulement, "ces malheureuses bourgades où tout est reculé de quatre à cinq siècles " appartenaient peu de temps auparavant au département du Léman, mais surtout cette criminalité était majoritairement le fait des ressortissants de ces campagnes. Aussi l'argumentation de Cougnard visant à discréditer toute tentative d'abolition de la peine capitale à Genève s'appuie-t-elle principalement sur la menace que représenteraient les populations rurales avoisinantes qui autrefois peuplaient le département du Léman.

9 Avant d'exposer les données chiffrées de la criminalité réprimée et de la peine capitale à Genève durant l'époque française, il convient de revenir brièvement sur la polémique qui a opposé François Cougnard au comte de Sellon. Un peu plus de dix ans après l'arrivée des troupes autrichiennes venues «libérer » Genève, cette opposition illustre les jugements divergents que l'on peut formuler à l'endroit du département du Léman et de ses institutions modernes en matière de pénalité. Cependant que Cougnard - et plus tard Massé - ne retiennent que la recrudescence des crimes, au détriment d'une réelle appréciation du nouveau système pénal, un philanthrope comme Sellon - qui, des terrasses de son domicile, pouvait observer la guillotine à chaque fois que l'échafaud était dressé - considère en revanche que "jamais époque ne fut mieux choisie à Genève pour une telle proposition [l'abolition de la peine de mort] $»^{15}$. Certes, les conditions nécessaires à l'abrogation, invoquées par le magistrat genevois, ne sont pas toutes un héritage direct du seul département du Léman; néanmoins, hormis le sentiment religieux si cher au comte de Sellon, tant « les lumières [...] léguées par le siècle précédent » que le principe d'une prison pénitentiaire sont clairement consacrés par le Code pénal de 1791. Dès lors, le débat engendré en 1826 par la question de l'abolition du châtiment suprême s'avère emblématique; il laisse en effet apparaitre en filigrane deux 
lectures antagonistes des conséquences, pour Genève, de l'annexion à la France révolutionnaire.

\section{Le département du Léman : un « repaire de brigands »?}

Outre la crispation identitaire engendrée par la perte de souveraineté, la forte hausse de la criminalité réprimée est sans doute l'un des aspects qui a le plus marqué les observateurs, contemporains comme postérieurs, du département du Léman. Et pour cause : du six nivôse an $\mathrm{VII}^{16}$ au quinze vendémiaire an X (soit de fin décembre 1798 à octobre 1801), vingt-six personnes sont condamnées à mort par le tribunal criminel du département du Léman. Sur ces vingt-six personnes, dix-sept sont exécutées, les neuf autres étant jugées en contumace ${ }^{17}$. Ainsi, en l'espace de trois ans, on observe à Genève plus d'exécutions capitales que durant toute la seconde moitié du XVIII ${ }^{\mathrm{e}}$ siècle; on dénombre en effet treize exécutions effectives pour la période allant de 1754 à $1798^{18}$. Est-ce à dire que Genève devenue française, chef-lieu d'un département de la République, se montrait plus sévère et plus encline à infliger la forme suprême du droit de punir que la Genève patricienne? L'homo criminalis avait-il plus à craindre la sentence de magistrats jugeant selon le nouveau code pénal de 1791 que l'arbitraire des juges d'Ancien Régime ${ }^{19}$ ? Toujours est-il que ce constat revêt un sens particulier, lorsque l'on sait que la peine capitale recule sensiblement à Genève tout au long du $\mathrm{XVIII}^{\mathrm{e}}$ siècle $^{20}$.

11 Cependant, établi sur les quinze années d'activité des juridictions criminelles successives du département ${ }^{21}$, ce constat d'un recours massif à la peine de mort doit être quelque peu relativisé : si la proportion de peines capitales prononcées par rapport au nombre d'individus jugés s'élève à $20 \%$ pour les années 1799-1801, elle chute sensiblement au cours des années suivantes et représente finalement $10 \%$ des peines prononcées durant la période observée ${ }^{22}$. Aussi, le fait de considérer l'évolution de la proportion de peines capitales prononcées permet-il de relativiser le recours à ce type de châtiment. Plus de la moitié des jugements capitaux rendus par les juridictions criminelles du département l'ont ainsi été au cours des trois premières années d'exercice (30 sur 59); pour le reste de la période, nous obtenons une moyenne d'un peu plus de 2 condamnés par an à cette sentence. De plus, abstraction faite des contumaces et autres jugements cassés, ce ne sont finalement « que » 16 individus qui périront sous la guillotine, de nivôse an X (décembre 1801) à décembre 1813.

12 Cette impression de progressive modération du recours au châtiment suprême est par ailleurs renforcée si l'on adopte une perspective comparative. Ainsi, il y eut en France 2,6 condamnations capitales pour 100000 habitants durant l'année 1801 - contre 8/100 000 à Genève - tandis qu'en 1811 la proportion est de 0,9/100 000 habitants en France, et chute à 0,5/100 000 dans le département du Léman ${ }^{23}$.

13 En outre, le taux impressionnant de condamnés envoyés à l'échafaud au cours de la période 1799-1801 coïncide avec le nombre élevé d'affaires de brigandage alors jugées, un type de contentieux qui entraîne généralement le châtiment suprême ${ }^{24}$. 
Graphique 1 : Brigandage, répartition des peines (valeurs et pourcentages)

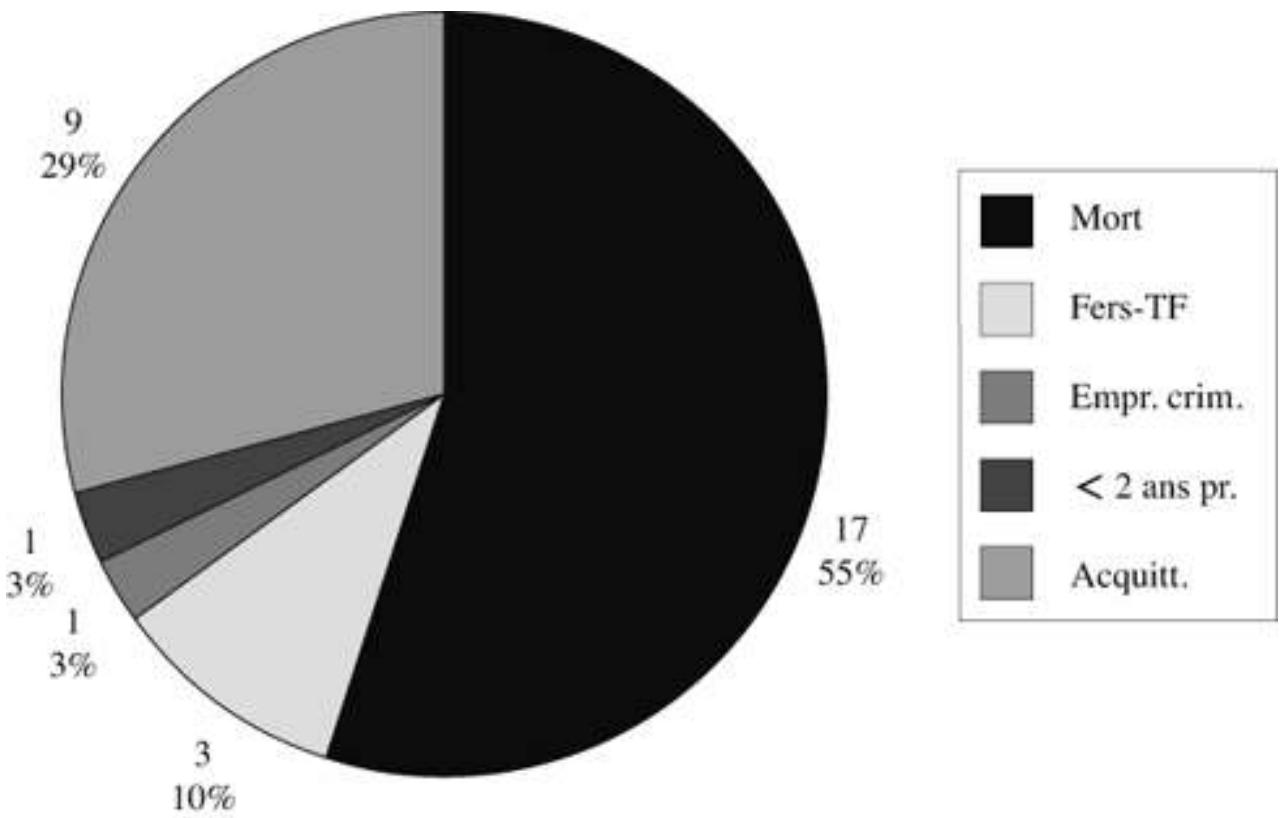

Les 31 individus qui ont comparu pour brigandage devant la juridiction criminelle du département du Léman pouvaient donc légitimement craindre le pire; de fait, $55 \%$ d'entre eux se verront condamnés à la guillotine. La gravité des crimes, le fait qu'ils sont commis en bande et sur des routes ou des chemins appartenant à l'État : toutes ces circonstances concourent à ce que les autorités criminelles fassent preuve d'une sévérité exemplaire ${ }^{25}$. De manière générale, le prévenureconnu coupable du crime de brigandage doit être condamné à mort ou acquitté. Nous pouvons en outre constater que les cinq individus ayant "bénéficié » d'une peine autre que la mort ont tous agi seuls ou en couple; ainsi, toutes les affaires de brigandage en réunion de plus de deux personnes ont abouti soit à la peine capitale, soit à l'acquittement.

En résumé, selon notre décompte, les juridictions criminelles successives du département du Léman ont condamné 59 personnes à la peine capitale de décembre 1798 à décembre 1813; parmi elles, 35 ont été exécutées. Le tableau suivant distingue succinctement, selon la juridiction, les raisons qui ont permis à 24 individus d'échapper au couperet de la guillotine ${ }^{26}$.

Tableau 1. Condamnés à mort, tableau récapitulatif : 1798-1813

\begin{tabular}{|l|l|l|}
\hline & Juridictions criminelles ordinaires & Juridictions criminelles spéciales ${ }^{27}$ \\
\hline Condamnés à mort & 56 & 3 \\
\hline Dont $:$ Contumaces & 21 & 1 \\
\hline Jugements cassés & 2 & \\
\hline Exécutés & 33 & 2 \\
\hline
\end{tabular}


16 Par ailleurs, de par le nombre bien plus élevé de forfaits de ce type par rapport au brigandage, près des deux tiers des individus condamnés à mort par les juridictions criminelles du département du Léman le sont pour des homicides (37 personnes sur $59)^{28}$. Le brigandage est à l'origine d'un peu plus du quart des condamnations capitales (17/59), alors que les atteintes aux biens n'engendrent plus aucune sentence suprême, si ce n'est à l'encontre des incendiaires (5/59).

17 En outre, en ce qui concerne la «sociologie » des condamnés à la peine capitale, le profil de l'homocriminalis sévissant dans le département lémanique présente des traits particulièrement prononcés: il s'agit presque systématiquement d'un homme, laboureur de profession et relativement jeune. En effet, seules cinq femmes se voient condamnées à mort, une seule d'entre elles étant en définitive guillotinée ${ }^{29}$. Fait par ailleurs singulier, plus de six condamnés sur dix (37/59) se déclarent laboureurs, au cours de leur procès ${ }^{30}$. Cependant, s'il est indéniable que l'immense majorité des individus frappés d'une condamnation à mort sont issus d'un milieu rural (trois seulement sont domiciliés à Genève intra muros), il convient de relativiser leurs dires. Ainsi certains prévenus sans profession peuvent-ils attester d'une activité par souci de ne pas paraître oisifs ou désœuvrés aux yeux des magistrats; dans ce cas, quoi de plus anodin et plausible qu'un habitant des campagnes exerçant le métier de laboureur ${ }^{31}$. Afin de compléter le portrait, notons que l'âge moyen des condamnés s'élève à 33 ans, sachant que nous ne disposons pas de données pour onze d'entre eux, tous contumaces.

La localisation géographique des crimes dont les auteurs sont condamnés à mort est instructive à plus d'un égard. Nous constatons ainsi que Genève intra muros n'est le théâtre d'infractions emportant le châtiment suprême qu'à deux reprises au cours des quinze années d'annexion à la France. L'homo criminalis puni de mort perpètre par conséquent ses forfaits dans les campagnes du département. Or, il s'avère que certains cantons abritent un nombre extraordinaire de crimes, comparativement à d'autres communes ou territoires. C'est notamment le cas au sein du triangle formé par les communes de La Roche, Bonneville et Reignier, espace passablement étréci au regard de la surface totale du département, mais dans lequel s'inscrit néanmoins une très forte proportion de forfaits entraînant la condamnation à mort de leur(s) auteur(s). Plus précisément, c'est à l'intérieur du périmètre formé par ce triangle qu'ont eu lieu la grande majorité des brigandages commis durant la période qui nous intéresse. Relevons en outre que, des individus exécutés, seuls trois ont commis leurs forfaits sur le territoire sis à la rive droite du Rhône. Enfin, nous sommes portés à croire que le nombre important de crimes perpétrés entre Bonneville et Genève coïncide avec la convergence des routes venant de Chambéry et du Piémont. Outre une activité économique probablement supérieure au reste du département (hormis Genève), cet axe présente également l'avantage d'offrir une issue vers les contrées voisines ${ }^{32}$. Cette impression est par ailleurs confirmée par une lettre du commissaire du Directoire exécutif, adressée au ministre de la Police générale, relative à la perméabilité des frontières du département :

Pour vous donner une idée des progrès effrayants de la désertion de l'armée d'Italie, je vous transmets, ainsi qu'au ministre de la Guerre, copie de trois lettres qui viennent de me parvenir de la part des Commissaires du Directoire exécutif des cantons de Cluses, Le Biot et Viry. Les lettres ne sont que la répétition des rapports que je reçois chaque jour et les faits qu'elles contiennent me sont d'ailleurs confirmés par les déclarations de tous les déserteurs que j'ai pu faire arrêter. Non seulement ils traversent l'Italie, le Piémont, les Alpes et ce département sans qu'ils 
éprouvent la moindre inquiétude, mais ils trouvent encore partout dans les campagnes accueil gracieux, secours et protection. Vous trouverez sans doute comme moi, Citoyen Ministre, les circonstances bien alarmantes dans un moment où les bruits les plus sinistres se répandent sur la situation de nos armées [...], où des troupes de brigands se sont déjà montrées dans plusieurs endroits et y ont commis des crimes atroces. J'ai souvent appelé l'attention du gouvernement sur la nécessité d'organiser promptement une forte gendarmerie dans ce département frontière ${ }^{33}$

\section{La guillotine genevoise ou l'acquisition d'un savoir- faire sophistiqué}

Le 24 floréal an VII (13 mai 1799), l'échafaud portant la guillotine est dressé « hors de la ville, sur les glacis de Plainpalais, près d'un ancien gros arbre placé au devant du chemin couvert des fortifications au bord de la route de Carouge $\aleph^{34}$. Lorsque le couperet tranche la nuque de Maurice Gervais ${ }^{35}$, c'est symboliquement tout le système punitif de la République française qui fond sur la Ville du bout du lac. La guillotine, figure emblématique de la justice révolutionnaire, fonctionne désormais à Genève; mais au delà d'une machine à décapiter, c'est l'ensemble du modèle français de justice qui est importé ${ }^{36}$.

Si, à la faveur de l'annexion, les troupes révolutionnaires françaises entraînent dans leur sillage un cortège d'institutions nouvelles, les instruments nécessaires à l'exécution des Arrêts criminels ne font pas partie du bagage. La responsabilité de la fabrication de la machine incombe en conséquence à l'administration lémanique, puisque, quatre jours après la condamnation à mort, le 26 février 1799, de Maurice Gervais, le bourreau genevois Jean-François Pasteur se voit rembourser une somme de 36 francs pour avoir transporté de Cluses à Genève "quelques pièces en bois de la guillotine $\aleph^{37}$. Une semaine plus tard, l'exécuteur se rend à Chambéry, chef-lieu du département voisin du Mont-Blanc, afin de faire confectionner un couperet; sa démarche échoue cependant, puisqu'on lui objecte que les tranchoirs sont fabriqués à Paris avant d'être envoyés à qui de droit ${ }^{38}$.

21 Toutefois, Pasteur ne mènera pas son projet à terme; bien qu'inconnues, les raisons de son désistement au profit d'un charpentier semblent néanmoins évidentes : s'il revient toujours au bourreau de procéder à l'exécution des Arrêts criminels, en réaliser l'instrument ne relève plus de sa compétence. Mêlant charpenterie, serrurerie, sellerie et forge, l'appareil du châtiment suprême n'a en effet jamais été aussi sophistiqué. L'administration du département décide donc de confier le soin de l'entreprise à un maitre charpentier du nom de Jean-François Nicolas Boiteux. À l'instar de l'exécuteur, l'artisan genevois entreprend le voyage de Chambéry afin d'examiner la machine et d'en prendre les mesures. Il apparaitt par ailleurs que Boiteux a travaillé à crédit pour le compte de l'administration centrale, puisqu'il a dû attendre plusieurs mois le remboursement intégral de son labeur. L'artisan devait de plus jouirde quelque liquidité car, outre le travail des bois effectué par ses ouvriers, Boiteux a dû s'acquitter lui-même des frais relatifs aux autres corps de métier. Le compte se révèle à ce propos assez précis: nous apprenons ainsi qu'il a fallu 42 journées à quatre ouvriers pour " [travailler] les bois en sapin pour l'échafaudage, de même que ceux en chêne pour la machine, faire les assemblages, monter lesdits et poser généralement toute la fermante $\star^{39}$. Un ouvrier étant payé 3 livres et 10 sols la journée, la main-d'œuvre 
nécessaire à la seule charpenterie s'élève, selon Boiteux, à 588 livres; si l'on ajoute à cela le prix des matières premières et des fournitures, la facture de l'« entrepreneur de bâtiments » se monte à 888 livres et 18 sols.

L'effort financier consenti par Boiteux ne s'arrête cependant pas là : en effet, celui-ci a également dû régler tant la main-d'œuvre que les fournitures des autres artisans associés à la construction de la machine à décapiter. Un décompte détaillé daté du 26 germinal an VII indique ainsi que «le citoyen Boiteux doit à Barnier serrurier, pour ouvrage fait à la guillotine » - à savoir la détente et le treuil du couperet, ainsi que les multiples écrous, boulons, tringles, ferrures, charnières et autres crochets nécessaires au fonctionnement comme au démontage de l'instrument - la somme de 302 livres et 7 sols $^{40}$. Le 17 floréal - soit une semaine avant l'exécution de Gervais - le sellier Jaquemet adresse à son tour sa note de frais au maître d'œuvre : il réclame 36 livres pour avoir peint la guillotine en rouge, 6 livres pour les courroies de la planche de la bascule, celles des barrières et celles du fourreau du couteau, ainsi que la même somme pour un tablier en cuir et pour le sac destiné à recevoir la tête du condamné. Enfin, moyennant la somme de 122 livres, le couperet est confectionné par Humel, forgeron à Commugny en Suisse. Le coût total de la guillotine genevoise s'élève donc à 1355 livres et 5 sols (toujours selon Boiteux) $^{41}$.

23 L'administration a en outre probablement déboursé davantage que la somme ci-dessus indiquée, car comme le précise le même document :

Le susdit Boiteux fera observer qu'il n'a ici aucun salaire pour ses peines et vacations, tant pour avoir été à Chambéry, que pour avoir été en Suisse pour le couteau, de même que pour faire tous les modèles pour les accessoires. Il laisse à la volonté de l'administration pour lui fixer un salaire à leur générosité, suivant ces peines $^{42}$.

Bien que nous ignorions le montant total que les autorités ont alloué à Boiteux, elles ont vraisemblablement apprécié son ouvrage. En effet, l'artisan est à nouveau sollicité en 1812 pour son savoir-faire. Outre son engagement à réparer la guillotine genevoise, il propose ses services, le 23 avril, à Joseph-Louis Brolliet, architecte mandaté par l'État :

Moi soussigné, entrepreneur des bâtiments d'artillerie de la Place de Genève, m'engage à construire tous les ouvrages qu'il y a à faire pour les exécutions criminelles, tant en charpente que maçonnerie, conformément au plan et devis qui ont été dressés à ce sujet, ayant pris entière connaissance desdits, de même que du cahier des charges, le tout pour le prix [...] de quatorze cents francs, y compris les fermants, etc. ${ }^{43}$

Si Boiteux se voit encore mis à contribution, ce n'est toutefois pas uniquement pour le compte de la seule administration lémanique. Celle-ci fait en la circonstance office d'intermédiaire entre le mandant et l'exécutant: le Préfet du récemment créé département du Simplon a en effet recours à l'expertise de son homologue genevois pour la fabrication des instruments nécessaires à l'exécution des jugements criminels, une tenue prochaine des Assises étant prévue dans ce département. Or, treize ans après les aléas de l'épisode genevois, l'administration française semble mieux préparée à faire face aux vicissitudes inhérentes à la réalisation d'une telle entreprise. Les ordres proviennent dorénavant du ministère de la Justice, comme l'indique une lettre du duc de Massa adressée au Préfet du Léman :

Le département du Simplon, Monsieur le Préfet, a besoin d'instruments et autres objets nécessaires pour l'exécution des arrêts criminels, et il n'existe dans ce département aucun ouvrier en état de le construire; je vous invite en conséquence à 
faire établir ceux de ces objets qui vous seront demandés par le Préfet de ce département. Il vous adressera à cet effet les réquisitions du Procureur impérial criminel près la Cour d'assises de Sion ${ }^{44}$. l'exécution de Maurice Gervais se déroule sur les Glacis de Plainpalais, il s'agit là de la première sentence capitale prononcée par le tribunal criminel du département. Or, à cette époque, l'administration centrale n'a pas encore définitivement déterminé l'emplacement de la guillotine ${ }^{47}$. Il semble cependant que, dès le second châtiment suprême, la machine à décapiter soit installée sur la place de la Porte de Neuve, au pied de l'hôtel particulier du comte de Sellon, entre le bas de la Tertasse et le bas de la Treille. Apparemment, l'instrument du supplice ne quittera Genève qu'à une seule reprise, pour être acheminé à Viuz en Sallaz le 20 août 1812, afin d'y mettre en application le jugement rendu par la Cour d'assises contre le nommé Baud-Berthier, condamné à la peine de mort pour faits de brigandage. Cette délocalisation de la guillotine est consécutive à une disposition du Décret impérial du 18 juin 1811, stipulant que l'exécution peut se faire dans la commune la plus proche du lieu où le crime a été commis.

Si nous connaissons l'emplacement sur lequel était dressé l'échafaud, le rituel de la mise à mort à Genève reste, lui, difficile à dépeindre; nous ne pouvons en effet que déplorer le manque d'indications concernant le déroulement de l'exécution des condamnés, hormis bien entendu les dispositions légales relatives à cet objet ${ }^{48}$. Aussi, 
ne pouvons-nous malheureusement restituer qu'un tableau lacunaire du "spectacle » coutumier du châtiment suprême :

Le cortège s'ébranle dans la matinée de la prison de l'Évêché, escorté par les cris de la foule, pour se rendre non loin de là sur la Place de la Porte de Neuve. Le condamné est accompagné à l'échafaud par des ministres du culte - protestants ou catholiques -, dont la présence est attestée tant par les dossiers du président du Tribunal criminel Le Fort que par le manuscrit de Jean-Élisée Massé ${ }^{49}$. Avant que le bourreau ne fasse son office, il semble que le futur supplicié puisse prendre la parole afin de témoigner sa repentance éventuelle ${ }^{50}$. Puis, celui-ci est lié debout à une planche basculante, avant d'être renversé à plat ventre. Fixée à une tablette horizontale glissant sur quatre rouleaux, la planche à bascule permet ainsi d'ajuster la lunette de la machine à la taille du condamné. L'exécuteur déclenche enfin la "simple mécanique » par laquelle s'abat le couperet qui, dans un bruit sourd, fait jaillir le sang de l'homo criminalis en même temps qu'il venge la société.

31 Alors que les dispositions relatives à l'exécution des jugements prononcés en conformité avec le Code pénal de 1791 - et avec la procédure correspondante - sont plutôt laconiques, le double souci affiché par l'Empereur d'un renforcement de l'autorité de l'administration et d'une meilleure gestion des deniers publics, conduit à organiser avec précision l'exécution des arrêts criminels. Ainsi le Règlement sur les frais d'exécution des Arrêts criminels ${ }^{51}$ vient-il compléter la profonde réforme de la justice répressive amorcée avec la promulgation du Code d'instruction criminelle en 1808 et rendue effective le $1^{\mathrm{er}}$ janvier 1811 , date de l'entrée en vigueur du Code pénal napoléonien. Fixant une véritable économie générale de l'exécution des jugements ressortissant aux cours d'assises, le Règlement assigne en détail les obligations qui incombent à chacune des figures concernées: préfet, procureur impérial criminel, ingénieur civil (et par voie de conséquence également menuisier et charpentier) et enfin exécuteur. Signe patent de la modernisation de l'appareil administratif français, cette directive répertorie par ailleurs la totalité des instruments et fournitures nécessaires, et ce jusqu'aux clous du cercueil :

\section{Article 2}

Les instruments servant aux exécutions, consistent: 1 . En un grand échafaud pour les exécutions à mort, avec son réservoir doublé en plomb / 2. En un petit échafaud pour les expositions / 3. En une machine à décapiter avec ses accessoires / 4. En poteaux pour les expositions / 5. En carcan avec leurs boulons, écrous, chaînes et cadenas / 6. En fers et réchaud pour la flétrissure.

Article 4

Les fournitures qui servent à plusieurs exécutions, sont : 1. Les paniers d'osier, doublés en cuir / 2. Les cordes, sangles et courroies / 3. Les balais / 4. Les planches pour les écriteaux.

\section{Article 5}

Les fournitures qui ne servent qu'à une seule exécution, sont : 1 . Les cercueils / 2. Les chemises rouges / 3. Le son, ou le sable, ou la sciure de bois / 4. Les écriteaux / 5. La graisse ou le savon / 6. Le charbon / 7. Les clous.

Outre la liste exhaustive des instruments et fournitures nécessaires, le Règlement sur les frais d'exécution des Arrêts criminels établit également l'ensemble des dépenses relatives à l'exécution desdits arrêts (article 1), soit: «1. Les frais de premier établissement des instruments servant aux exécutions; 2. Les frais d'entretien, réparation, transport, placement et déplacement de ces instruments; 3 . Le transport des condamnés tant au lieu du supplice qu'au lieu de l'inhumation; 4. Les fournitures relatives aux exécutions; 
5. Les frais de déplacement des exécuteurs et le transport des instruments dans les lieux où les exécutions doivent se faire ».

Ainsi, en considérant presque sans distinction personnel et matériel, ce document opère une formidable distanciation avec l'objet qu'il réglemente; hommes ou fournitures, tous participent en définitive d'un processus qui semble leur échapper. La figure du bourreau, qui emportait l'infamie durant l'Ancien Régime, ne constitue plus qu'un rouage dans la mécanique des exécutions, au même titre que l'ingénieur civil ou que le panier d'osier dans lequel choit la tête du condamné après que le couperet est tombé ${ }^{52}$. Paradoxalement, l'acteur principal du supplice légal n'est mentionné qu'à deux reprises dans le Règlement (articles 1 et 16) : d'une part en ce qui concerne ses frais de déplacement et, d'autre part, en rapport avec l'abonnement qu'il doit contracter afin d'assurer la fourniture des objets détaillés dans les articles 4 et 5 . Or, aucune disposition ne traite explicitement du véritable office de l'exécuteur, ni de son coût. Au vu du Règlement, le bourreau s'éclipse de facto derrière l'appareil du supplice. C'est à la guillotine, désormais protagoniste à part entière, que revient la charge de la mise à mort. Son subalterne et servant veillera à ce que les fournitures soient de bonne qualité et en nombre suffisant, comme l'indique cette soumission de l'exécuteur genevois Isaac Pasteur :

Je m'engage à fournir et entretenir les fournitures désignées dans l'article 4 et 5 du Règlement, en conformité de l'article 113 du Décret impérial du 18 juin 1811, pour la somme de 400 francs par année $e^{53}$.

Isaac Pasteur à Genève, comme tant d'autres exécuteurs en France, endosse in fine le rôle de simple pourvoyeur de matériel. Son seul rapport avec la guillotine réside dès lors dans l'actionnement d'une machine qui lui devient presque étrangère. Ceci d'autant plus que l'entretien, les réparations, le transport et le montage des instruments nécessaires aux exécutions font également l'objet d'un abonnement, qui, de par la complexité de l'appareil, ne peut être contracté que par un artisan qualifié.

Comme pour la construction de la guillotine, le prix des abonnements est âprement négocié par le préfet; afin d'emporter le marché, le charpentier Gélaz fait ainsi valoir son savoir-faire en la matière, lui qui se charge du montage et du démontage de l'échafaud depuis quatre ans ${ }^{54}$. Il faut cependant croire que son expérience ne suffit pas, puisqu'une note manuscrite datée du 17 mars 1813 indique qu'«il est dû à Antoine Didier, charpentier, pour avoir fait conduire le grand échafaud sur la place des exécutions pour le dernier condamné à mort le nommé François Perron : 10 francs. Pour monter et démonter ledit : 36 francs. Idem pour faire laver ledit échafaud après l'exécution du susnommé : 3 francs $»^{55}$. Finalement, le rôle secondaire endossé par l'exécuteur se traduit aussi par le salaire qu'il perçoit; alors que l'administration genevoise accorde au charpentier Didier la somme de 49 francs pour la tâche exposée ci-dessus, Isaac Pasteur n'obtient «que » 24 francs "pour s'être transporté le 20 août 1812 à Viuz en Sallaz, chef-lieu de canton de l'arrondissement de Bonneville, pour y mettre à exécution le jugement rendu le 15 juin par la Cour d'Assises contre le nommé Étienne Baud-Berthier condamné à la peine de mort $»^{56}$.

\section{Acculturation versus résistance}

Pour conclure, nous observerons comment Genève s'est accommodée de l'exportation d'un paradigme punitif moderne, sur la base de quelques exemples révélateurs. 
L'acceptation, aussi bien que le rejet d'un modèle de justice imposé sont ici appréhendés, tant au travers de la pratique des juridictions pénales lémaniques que par le biais de l'expression de la sensibilité de certains magistrats genevois.

Parmi ceux-ci, les sources qu'il nous a été donné de consulter ont mis en évidence la figure du président du Tribunal criminel du département du Léman. Bien plus que le procureur Girod, dont les réquisitoires n'ont pu être étudiés ${ }^{57}$, c'est ainsi le président Jacques Le Fort qui se révèle le magistrat le plus disert quant à la philosophie punitive incarnée par le Code pénal de 1791. S'il faut opérer une distinction, chez Le Fort, entre le professeur de Droit et le magistrat, il s'avère néanmoins que son regard sur la justice révolutionnaire française témoigne d'une incontestable continuité avec l'Ancien Régime genevois autant qu'il atteste différents éléments de rupture.

Manifestement influencé par les philosophes des Lumières (lecteur de Montesquieu, Beccaria, mais aussi Filangieri et Duport), sincèrement animé de sentiments philanthropiques et favorable à une modération du recours au châtiment suprême, le président du Tribunal criminel émet toutefois de sérieuses réserves quant à la légalité des délits et des peines, principe pourtant considéré comme inaliénable par les constituants de 1791. Favorable, selon toute vraisemblance, au système judiciaire anglais, il dénonce la perversité d'une justice de citoyens jurés, susceptible à ses yeux de trop fluctuer et de fréquemment acquitter des accusés «évidemment coupables ». Le Fort préconise ainsi l'arbitraire, comme « une imperfection nécessaire [...] qui corrige celles qui se trouvent et se trouveront toujours dans la jurisprudence criminelle ${ }^{58}$; souhaitant « laisser aux juges un peu plus d'ascendant », il se trouve par conséquent en porte-à-faux avec l'esprit du droit de punir désormais consacré. En définitive, sa proposition de substituer la pendaison à la décapitation par la guillotine montre l'attachement porté à certains usages de la Genève patricienne, en même temps qu'elle témoigne d'une résistance aux pratiques nouvelles. Précisons toutefois que cette proposition formulée par Le Fort dans le Discours sur l'institution du Jury a également fait l'objet, en 1804, d'une remarque exprimée alors collectivement par les membres du Tribunal criminel dans les «Observations du Tribunal criminel du Léman sur le Projet de Code criminel » :

Loin de nous l'idée de rétablir des supplices cruels! Mais n'y aurait-il pas quelques avantages à remplacer la guillotine par la potence, sans présenter aux yeux le spectacle horrible du sang qui coule sur la place de l'exécution? Ce genre de mort frappe davantage les spectateurs, et augmente par là l'efficace [sic] de l'exemple, principal but des condamnations: ce corps que l'on a vu se débattre et qui reste là suspendu, fait bien plus d'impression sur la multitude que cette opération instantanée, qui, faisant disparaître en un clin d'œil le corps du supplicié, paraît plutôt un coup de théâtre qu'une exécution ${ }^{59}$.

Autre élément de continuité avec l'Ancien Régime genevois et signe manifeste que le rituel judiciaire persiste à solliciter la caution religieuse, l'exhortation du condamné est prononcée après le jugement et constitue de la sorte l'acte final du procès. Si l'origine et le sens - de l'exhortation revêtent un caractère essentiellement religieux ${ }^{60}$, et s'il était fréquent, au cours des siècles précédents, que les ministres du culte exhortassent les condamnés à mort à la résignation, le fait qu'un tel sermon soit désormais prononcé par un magistrat dans l'enceinte même du Tribunal criminel peut interloquer à plus d'un titre. Sécularisée depuis peu, la justice pénale a en effet pris grand soin d'affranchir les contentieux réprouvés de tout caractère religieux, et les hommes d'Église ne sont éventuellement sollicités que pour assister un condamné à mort dans 
ses dernières heures. Or, le président Le Fort exhorte systématiquement l'homo criminalis voué à l'échafaud, et ceci sans qu'il soit légalement tenu de le faire. Nous ne trouvons effectivement aucune disposition de cet ordre dans les textes de lois relatifs à la procédure ${ }^{61}$. C'est donc de son propre chef que le magistrat genevois enjoint les futurs suppliciés à "tourner leurs pensées vers cet avenir qui est au delà du tombeau $»^{62}$. Bien qu'avant tout religieux, le propos de l'exhortation s'avère cependant double :

Jean Méry et Jacqueline Léger, pour m'acquitter des derniers devoirs que la loi m'impose, il ne me reste plus qu'à vous exhorter à la fermeté et à la résignation. On ne saurait en avoir un plus grand besoin, le souvenir de votre conduite [passée], votre état d'époux et vos remords rendent votre situation affreuse. Vous avez pourtant le droit de recourir en cassation et vous avez trois jours pour faire votre déclaration d'appel, dix pour en préparer les moyens, et quelques semaines ensuite pour en attendre le résultat.

Ainsi, "pour [s]'acquitter des derniers devoirs que la loi impose», le président rappelle-t-il l'ultime voie de recours qui s'offre aux condamnés, tout en soulignant le caractère vain d'une telle démarche :

Je sais tout ce qu'a de cruel cet intervalle partagé entre beaucoup de crainte mais peu d'espérance. Mais il peut être pour vous encore plus précieux que pénible; car ce n'est plus ici bas que vous pouvez trouver des consolations, il faut désormais tourner vos idées vers le ciel et implorer sa miséricorde. Des hommes pieux et zélés vous [visiteront] avec zèle et assiduité; ils vous aideront à rentrer en vous-même et à mériter par un repentir profond et sincère que le Dieu des miséricorde ait pitié de vous. [...] Si votre vie a été une leçon de scandale pour vos enfants, puisse du moins votre mort devenir pour eux une leçon de vertu aussi efficace qu'elle est terrible ${ }^{63}$.

41 À la lecture de la dizaine d'exhortations recensées dans les Résumés, le caractère religieux de l'acte final du procès est manifeste. Après la sentence, à l'heure d'exposer au prévenu la possibilité d'interjeter appel de son jugement, le magistrat genevois consacre systématiquement son discours à l'édification de l'homo criminalis. Il enjoint par ailleurs les condamnés à considérer le pourvoi en cassation non pas comme un éventuel espoir de salut temporel, mais comme un simple sursis provisoire à l'exécution, ultime opportunité d'un repentir «aussi profond que sincère » avant le Jugement dernier :

Jusqu'à présent vous vous êtes peu occupés d'idées religieuses; privés pendant les orages de la Révolution des ressources d'un culte public, vous avez peu cherché à y suppléer dans votre particulier. Celui qui n'aime point son frère qu'il voit, comment aimerait-il Dieu qu'il ne voit point? dit l'écriture. Mais il en est peut-être temps encore, si vous profitez de la faculté de vous pourvoir en cassation. La loi vous donne trois jours pour décider, il en est temps, cherchez ce Dieu que vous avez trop négligé, laissez, laissez toutes les [considérations] de ce monde pour ne vous occuper que de votre salut éternel; détachez vos yeux de [dessus] cette terre où les objets d'affection qui vous y restent ne peuvent que rendre le sentiment de votre [position] plus douloureux et votre séparation plus déchirante. Tournez vos regards vers cette vie nouvelle où vous allez entrer, aidez-vous de tous les secours que la religion et le zèle de ses ministres vous présenteront. Pleurez sur vos fautes, humiliez-vous, repentez-vous, vous pouvez tout espérer de l'[efficace] du repentir sincère et profond ${ }^{64}$.

Ainsi la dévotion du magistrat genevois prend-elle en quelque sorte le pas sur sa charge. Du moins met-il à profit la latitude que lui donne le discours conclusif du procès pour exhorter le condamné à la résignation et à la repentance. S'il s'acquitte des obligations prescrites par la loi en mentionnant la possibilité de recours, Le Fort 
considère l'espoir d'une éventuelle cassation comme chimérique. Seuls comptent désormais les secours des "hommes pieux et zélés", agents de Dieu grâce auxquels l'homo criminalis pourra acquérir « la seule consolation qui puisse avoir quelque [office], celle de la Religion, celle d'un Dieu miséricordieux qui daigne peut-être pardonner, s'il juge [le] repentir aussi sincère et profond que [les] crimes ont été énormes $»^{65}$.

Cependant, au delà de la sensibilité et des convictions du seul président du Tribunal criminel, la dualité entre résistance et acculturation se révèle patente pour l'ensemble du personnel judiciaire. Toutes les figures concernées par la justice pénale ont en effet été contraintes de s'accommoder tant à l'esprit qu'aux pratiques d'un système punitif allogène. À Genève comme dans les autres territoires nouvellement annexés, la confrontation entre le modèle français de justice et les traditions juridiques et pénales locales n'a pas manqué de susciter autant l'adhésion que le rejet ${ }^{66}$. Dès lors, nous avons observé un véritable processus d'apprentissage, lequel se vérifie pour l'ensemble des individus intéressés au fonctionnement de la justice répressive. Relatives à la procédure, au jugement ou encore à l'exécution des arrêts criminels, les difficultés rencontrées par le personnel judiciaire lémanique ont été légion. Aussi, comme nous l'avons vu, le bourreau Jean-François Pasteur a-t-il été contraint de se familiariser avec une technique suppliciaire "étrangère ", abandonnant par là même son savoir-faire antérieur ${ }^{67}$.

Habitué à une administration de proximité, le président Le Fort n'a pas jugé bon, en 1800, de se faire nommer au Tribunal d'appel de Lyon avant d'exercer ses nouvelles fonctions; ayant agi au mépris de la loi, le magistrat genevois doit ainsi essuyer les remontrances de son ministre tutélaire dès les premiers jours de sa nomination :

Je ne partage pas, Citoyen, l'opinion d'après laquelle vous avez cru pouvoir entrer en exercice des fonctions de président du Tribunal criminel, avant de vous faire installer juge au tribunal d'appel: le vœu de la loi sur l'ordre que vous aviez à suivre me paraît exprimé positivement par l'article 3 de la loi du 27 ventôse dernier. Il en résulte que le $1^{\text {er }}$ Consul doit choisir tous les ans le président du Tribunal criminel parmi les juges du Tribunal d'appel. [...] Je vous invite à ne pas différer à remplir cette formalité qui n'est pas une vaine cérémonie.

Et le ministre de poursuivre :

Je n'entends pas néanmoins rien préjuger sur la validité des jugements auxquels vous avez concouru antérieurement. Ce serait au tribunal de cassation à prononcer si l'on en demandait la cassation ${ }^{68}$.

Il ne s'agit toutefois pas de la seule liberté prise par Le Fort par rapport à la procédure, puisque, en 1811, le magistrat genevois se retrouve à nouveau en délicatesse avec les principes de la «justice moderne ». Ainsi, après avoir échangé, en 1804, son poste de président du Tribunal criminel avec Marc-Jules Pictet Diodati, député du corps législatif à Paris, Jacques Le Fort reprend en 1810 ses fonctions de président du Tribunal criminel, avant d'être nommé président du Tribunal d'instance l'année suivante. $\mathrm{Si}$, «du fait des habitudes prises $»^{69}$, cette permutation semble ne pas être problématique, le fait que Le Fort ait, peu de temps auparavant, fait nommer son fils Jean-Louis au poste de substitut du procureur pose en revanche un sérieux problème d'incompatibilité de parenté; or, non seulement le magistrat genevois à son retour à la présidence du Tribunal criminel ne demandera pas la récusation de son fils, mais il fera de plus accepter la nomination de son cousin Jean-Antoine Claparède à la viceprésidence de son tribunal. Cette incompatibilité de parenté au sein même d'une des plus hautes juridictions est d'autant plus surprenante, sachant que trois ans 
auparavant, au cours d'une affaire qui connut un grand retentissement, le dénommé André-Louis Rosset fut condamné à mort, puis acquitté par la Cour de cassation; et pour cause : le substitut du commissaire du Gouvernement, le citoyen Frarin, n'avait pas cru devoir se désister de cette affaire, alors que son épouse présentait des liens de parenté avec la victime. Le conflit d'intérêt avait semble-t-il échappé au magistrat, mais pas aux défenseurs des frères Rosset, lesquels ont tout naturellement obtenu la cassation du jugement.

Autre exemple frappant de la persistance d'usages pénaux censément révolus, le procureur Girod a, sans en référer à sa hiérarchie, décidé en 1806, de faire procéder à la décapitation du cadavre de Jean Condevaux, condamné qui s'est suicidé en prison. Pour justifier son opiniâtreté et afin que le zèle dont il a fait preuve se voie légitimé en haut lieu, Girod expose au ministre de la Justice les raisons de ce macabre spectacle :

Les ordres pour son exécution étaient donnés et son corps a été conduit à l'échafaud où il a eu la tête tranchée. Quoique ce cas ne soit pas textuellement prévu, j'ai pensé que l'appareil du supplice et la décapitation du suicidé n'en seraient pas moins utiles pour l'exemple, et qu'il en résulterait surtout le bon effet d'apprendre au public que tous les moyens que pourraient mettre en œuvre soit le condamné, soit ses parents où ses amis pour le soustraire à la honte et à la publicité du supplice ordonné par la loi seraient inutiles ${ }^{70}$.

Plutôt satisfait de son entreprise, le représentant du ministère public souligne les finalités d'un tel acharnement. D'abord l'exemplarité : soumettre l'appareil du supplice ainsi que son usage - indépendamment de l'état du condamné - au regard du public doit permettre d'édifier la foule et de lui signifier l'omnipotence et la souveraineté de l'État. La publicité et la honte, autres buts assignés au supplice de l'homo criminalis, sont par ailleurs garanties. Enfin, le procureur souhaite démontrer ainsi que nul ne peut échapper à la justice de l'Empire et à la certitude de son châtiment :

En dernière analyse, la volonté du condamné définitivement, qui se tue, serait-elle plus forte que la loi, ou celle-ci ne doit-elle pas planer encore sur la partie du condamné restée soumise aux sens de la société qui doit être vengée? Si je me suis trompé, je vous prie de me le faire savoir, afin qu'en pareille circonstance je me conduise différemment ${ }^{71}$.

Le zèle ayant probablement pris le pas sur le strict respect de la loi, il a fallu attendre l'admonestation du Grand Juge pour que le commissaire du Gouvernement saisisse l'ampleur de son erreur :

Vous avez dépassé le but, Monsieur, en faisant conduire sur l'échafaud et décapiter le cadavre du nommé Condevaux, condamné qui s'était suicidé. La justice n'a plus de rigueur à exercer sur les restes d'un criminel qui a cessé de vivre. La mort, soit volontaire, soit naturelle, éteint toute action de la vindicte publique.

Là encore, nous pouvons mesurer la rémanence de certaines pratiques d'Ancien Régime, de même que nous apparaît clairement la difficulté éprouvée par d'aucuns à saisir l'esprit d'une culture juridique nouvelle. Enfin, l'analyse quantitative du fonctionnement des juridictions criminelles du département s'avère également révélatrice quant à la persistance ou à l'abandon de certains usages pénaux d'avant la Révolution. Ainsi, conformément à la construction de typologies d'infractions établie plus haut - comprenant la distinction entre les crimes contre les individus, les crimes contre les biens, les atteintes à l'État, etc. - nous observons des résultats significatifs à plus d'un égard. En ce qui concerne les crimes contre les biens (vols, faux, et autres recels), la répartition des peines considérée dans le temps atteste d'un recours progressif à l'emprisonnement criminel au détriment des travaux forcés. À mesure que 
l'on avance dans le temps, l'incarcération occupe en effet une place grandissante, avant de s'imposer massivement avec l'entrée en vigueur du Code pénal de 1810. personnes; certes, le recours au châtiment suprême se fait de plus en plus rare, mais nous constatons toujours une proportion importante de travaux forcés. À croire que l'emprisonnement criminel ne satisfaisait pas, aux yeux des magistrats du tribunal criminel du département, les exigences de sévérité et d'exemplarité nécessaires à la punition des crimes de ce type; comme si un souci d'analogie entre la violence du crime et la cruauté de la peine présidait encore au choix de la sanction.

Ressort juridique - pour les premières années d'activité du Tribunal criminel - d'un recours massif au châtiment suprême et considéré par les observateurs du XIX ${ }^{\mathrm{e}}$ siècle comme un creuset de la criminalité, le département du Léman a longtemps pâti d'un jugement hâtif et défavorable. Ces opinions préconçues ne résistent cependant pas à l'examen du fonctionnement des juridictions criminelles lémaniques; si l'on observe, de 1799 à 1801, un nombre significatif d'individus exécutés pour brigandage, la modération progressive du recours à la peine capitale s'avère toutefois incontestable sur l'ensemble de la période étudiée. En revanche, ce qui se révèle communément ignoré, voire occulté, et qui confère pourtant une influence essentielle aux juridictions criminelles du département du Léman en inscrivant Genève dans un processus de modernité, réside dans la métamorphose de la structure étatique et de ses corollaires : intense organisation administrative, forte centralisation et avant tout modification des rapports entre État, Justice et citoyens. Aussi, au delà de la crispation identitaire engendrée par la perte de souveraineté, l'annexion à la France coïncide-t-elle, pour Genève, à un pas notable vers l'affirmation de l'État de droit. 


\section{Sources manuscrites}

\section{Archives d'État de Genève (ci-après AEG)}

Arrêtés de l'Administration centrale du département du Léman (AEG, ADL A 12), 1798-1799.

Copies de lettres de l'Administration centrale(AEG, ADL A 15), 1798-1799.

Copies de lettres du commissaire du Pouvoir exécutif auprès de l'Administration centrale du département du Léman(AEG, ADL A 37), 1799.

Copies de lettres du commissaire du Pouvoir exécutif auprès de l'Administration centrale du département du Léman(AEG, ADL A 40), 1799.

Frais de justice(AEG, ADL B 684k), 1812-1813.

Greffe criminel : registre des jugements du Tribunal criminel (AEG, ADL J 59 à 61), 1798-1804.

Greffe criminel : registre des arrêts rendus par la Cour de justice criminelle (AEG, ADL J 62 à 64), 1804-1811.

Greffe criminel : registre des arrêts rendus par la Cour d'Assises (AEG, ADL J 65), 1811-1813.

LE FORT, J., Discours sur l'institution du Jury,prononcé aux promotions de l'Académie de Genève, le 15 juin 1801. AEG, Archives de famille Le Fort, $1^{\mathrm{e}}$ série, nouveau fonds, 3.

Liasses diverses(AEG, ADL CXCVII), 1796-1801.

MASSÉ, J.-É., Relevé statistique des condamnations criminelles portant peine de mort prononcées par le Tribunal criminel français de 1799 à 1814. Exécutions et contumaces (AEG, Manuscrit historique 338/6), [1864-1870].

Prisons : correspondance(AEG, ADL B 788), 1798-1813.

\section{Bibliothèque de Genève (ci-après BGE)}

LE FORT, J., Résumé des causes criminelles, an IX-an XIII puis 1810-1811, BGE, Ms suppl. 246 à 253.

\section{Archives Nationales françaises (ci-après AN)}

Correspondance générale de la division criminelle (AN, BB18 420 à 422), an 2 - 1816.

Organisation de la justice et personnel judiciaire dans les pays réunis pendant la Révolution et l'Empire : Allemagne, [...], Savoie, Comté de Nice, Suisse (AN, BB5 327), 1793-1816.

\section{Sources imprimées}

Annuaire du département du Léman pour l'année 1811,Genève, Paschoud, 1811.

Annuaire du département du Léman pour l'année 1814,Genève, Paschoud, 1814.

COUGNARD, F., Du maintien de la peine de mort dans le canton de Genève, Genève, Lador, 1826.

DUCPÉTIAUX, É., De la peine de mort : de la mission de la justice humaine et de l'influence de la peine de mort. De la justice de répression et particulièrement de l'inutilité et des effets pernicieux de la peine de mort, Bruxelles, Tarlier, 1827. 
DUCPÉTIAUX, É., Statistique de la peine de mort en Belgique, en France et en Angleterre,Bruxelles, [s.n.], 1835.

GIROD, J.-B.M., Conclusions prononcées dans la cause des frères André-Louis et Pierre-Louis Rosset, de la commune de Viry par M. Girod, procureur général impérial près la cour de justice criminelle du Département du Léman, membre de la Légion d'honneur, [s.l.], [s.n.] 1808.

LUCAS, Ch., Du système pénal et du système répressif en général, de la peine de mort en particulier, Paris, Béchet, 1827.

NAVILLE, F.-A., État civil de Genève, Genève, Barde, 1790.

«Observations du tribunal criminel du Léman, sur le projet de code criminel », in Observations sur le projet de code criminel de l'an XI, par les cours de justice criminelle, t. III, Paris, [s.n.], an XIII.

Règlement sur les frais d'exécution des Arrêts criminels, dressé en conformité de l'article 113 du Décret impérial du 18 juin 1811.

SELLON, J.-J. (de), Avis : un concours est ouvert à Genève en Suisse en faveur de l'abolition de la peine de mort, Genève, [s.n.], 1826 a.

SELLON, J.-J. (de), Un mot sur la proposition de M. J.-J. De Sellon, pour la suppression de la peine de mort, suivi des points principaux qui doivent être traités dans le concours, et de quelques fragments sur ce sujet, Genève, Lador, $1826 \mathrm{~b}$.

SISMONDI, J.-Ch.-L. S. (de), Statistique du Département du Léman [1801], publiée d'après le manuscrit original et présentée par H. O. Pappe, Genève, Jullien, 1971.

Traité de réunion de la République de Genève à la République Française, Genève, [s.n.], 1798.

\section{Références}

ALLEN, R., Les tribunaux criminels sous la Révolution et l'Empire : 1792-1811,Rennes, PUR, 2005.

ARASSE, D., La Guillotine et l'imaginaire de la Terreur,Paris, Flammarion, 1987.

AUBUSSON DE CAVARLAY, B. et al., La pratique des juridictions criminelles du département de Sambre-et-Meuse à l'époque française (1796-1815) - une analyse quantitative in ROUSSEAUX, X., DUPONT-BOUCHAT, M.-S., VAEL, C. (dir.), Révolutions et Justice pénale en Europe : modèles français et traditions nationales (1780-1830), Revolution and Criminal Justice in Europe, 1780-1830. French Models and National Traditions, Paris, L’Harmattan, 1999, pp. 199-223.

BADINTER, R., (dir.), Une autre justice : 1789-1799, Contribution à l'histoire de la justice sous la Révolution française,Paris, Fayard, 1989.

BOUVET, S., «Le silence des abeilles. L'identité genevoise, ses enjeux politiques et culturels face à l'annexion française (1798-1813) ", mémoire de licence dactylographié, Lettres, Genève, 1997.

BRIEGEL, F., PORRET, M., Le droit de punir en République : Genève au temps des Lumières, Dixhuitième siècle, « Politique et culture ", 2005, 37, pp. 69-85.

CHAUVAUD, F., Les criminels du Poitou au XIX ${ }^{e}$ siècle,La Crèche, Geste éd., 1999.

DELARUE, J., Le métier de bourreau, Paris, Fayard, 1979.

DENYS, C., Frontière et criminalité : 1715-1815, Arras, Artois Presses Université, 2001.

EGMOND, F., Underworlds. Organized crime in the Netherlands : 1650-1800, Cambridge, Polity Press, 1993. 
DUVERGIER, J.-B., Collection complète des lois, décrets, ordonnances, règlements, et avis du Conseil d'État,tome III,Paris, Guyot, 1824-1826.

LASCOUMES, P., PONCELA, P., LENOËL, P., Au nom de l'ordre. Une histoire politique du code pénal,Paris, Hachette, 1989.

MARTSCHUKAT, J., Inszeniertes Töten : Eine Geschichte der Todesstrafe vom 17. bis zum 19. Jahrhundert, Köln - Weimar - Wien, Böhlau, 2000.

MAUGUÉ, L., Criminalité réprimée et peine capitale à Genève durant l'époque française (1798-1813), mémoire de licence dactylographié, Lettres, Genève, 2006.

MOTTU-WEBER, L., DROUX, J. (dir.), Genève française 1798-1813, Actes du colloque de Genève [1998], Genève, SHAG, 2004.

PALLUEL-GUILLARD, A., L'Aigle et la croix. Genève et la Savoie 1798-1815, Yens sur Morges - SaintGingolph, Cabédita, 1999.

PETIT, J.-G., Ces peines obscures. La prison pénale en France (1780-1875), Paris, Fayard, 1990.

PORRET, M., Au lendemain de l'« affaire Rousseau », la « justice pervertie » ou les représentations de la justice patricienne chez quelques publicistes de Genève 1770-1793, in BINZ, L., BACZKO, B., NEUENSCHWANDER, M., LABARTHE, O., DURAND, R., (dir.), Regards sur la Révolution genevoise, 1792-1798, Genève, Droz, 1992, pp. 119-150.

PORRET, M., Genève républicaine au XVIII ${ }^{\mathrm{e}}$ siècle : réalité des représentations et représentations de la réalité, in BUSCAGLIA, M. (dir.), Charles Bonnet savant et philosophe (1720-1793), Genève, PasséPrésent, 1994, pp. 3-17.

PORRET, M., Le crime et ses circonstances. De l'esprit de l'arbitraire au siècle des Lumières selon les réquisitoires des procureurs généraux de Genève, Genève, Droz, 1995.

PORRET, M., Genève, de République à préfecture, in GREGORI, M., MARCACCI, M., PHILIPONA, C., (dir.), La double naissance de la Suisse moderne. De la République à l'État fédéral,Genève, S. Hurter, 1998, pp. 56-61.

REY, A., (dir.), Dictionnaire culturel en langue française, Paris, Dictionnaires Le Robert, 2005.

ROTH, R., Pratiques pénitentiaires et théorie sociale : l'exemple de la prison de Genève : 1825-1862, Genève, Droz, 1981.

ROUSSEAUX, X., DUPONT-BOUCHAT, M.-S., VAEL, C. (dir.), Révolutions et justice pénale en Europe : modèles français et traditions nationales (1780-1830), Revolution and Criminal justice in Europe, 1780-1830. French Models and National Traditions, Paris, L'Harmattan, 1999.

SCHNAPPER, B., Compression et répression sous le Consulat et l'Empire, Revue historique de droit français et étranger, 1991, 69, 1, pp. 17-40.

SCHNAPPER, B., Les systèmes répressifs français de 1789 à 1815, in ROUSSEAUX, X., DUPONTBOUCHAT, M.S., VAEL, C. (dir.), Révolutions et Justice pénale en Europe : modèles français et traditions nationales (1780-1830), Revolution and Criminal justice in Europe, 1780-1830. French Models and National Traditions, Paris, L'Harmattan, 1999, pp. 17-32.

ZURBRUCHEN, W., La guillotine de Genève, Musées de Genève,1971, 120, pp. 15-17.

ZURBRUCHEN, W., La guillotine de Genève (suite), Musées de Genève,1972, 121, pp. 13-15. 


\section{NOTES}

1. Cet article prolonge un mémoire de licence en histoire moderne dirigé par le Professeur Michel Porret et présenté à la Faculté des Lettres de l'Université de Genève en juillet 2006 : Maugué (2006) (Prix Ador 2007). Il annonce une thèse sur la justice dans le département du Léman.

2. Les rares travaux consacrés à cette époque ont presque exclusivement été publiés durant les vingt premières années $d u \mathrm{XX}^{\mathrm{e}}$ siècle et émanent souvent d'une historiographie à plus d'un titre révolue. Si le département du Léman a fait l'objet de quelques études au cours des dix dernières années, les deux seuls ouvrages édités - Palluel-Guillard (1999) et Mottu-Weber, Droux (2004) n'abordent que très peu les problématiques que nous souhaiterions développer dans le cadre de cet article. Pour une bibliographie thématique des travaux portant sur le département du Léman, on se référera à la recherche de Palluel-Guillard (1999). Voir aussi la riche bibliographie de Bouvet (1997).

3. Traité de réunion de la République de Genève à la République Française. Le 26 avril 1798, le Directoire ratifie le traité de réunion qui lie de force Genève à la France. La Cité du bout du lac doit dès lors renoncer à sa souveraineté comme à ses alliances et remettre à la «Grande Nation » ses fortifications, ses arsenaux et son artillerie. Bientôt simple chef-lieu du département du Léman (25 août 1798), Genève se retrouve sous l'empire des lois françaises et fait progressivement l'objet d'une intense réorganisation administrative. Autre disposition notable: les Genevois sont désormais déclarés « Français nés ».

4. Fort d'une population d'environ 210Times000 habitants et recouvrant le territoire de l'ancienne République ainsi que des parties détachées des départements voisins de l'Ain et du Mont-Blanc, le département du Léman se trouve alors «situé aux frontières orientales de la République française, [...] confiné au nord par le Canton helvétique du Léman, au levant par le Piémont, au midi par le département du Mont-blanc, et au couchant par celui de l'Ain », in Sismondi (1971, p. 67).

5. Citons les mesures les plus remarquables de cette philosophie pénale moderne : légalité des délits et des peines, classification rationnelle et laïcisation du contentieux, rejet des châtiments physiques marquant d'infamie le corps des criminels, publicité de la procédure, non rétroactivité des peines, etc., Lascoumes et al. (1989), Badinter (1989). Pour le Consulat et l'Empire, Schnapper (1991, 1999).

6. «L'ordre a été constamment maintenu dans le Département du Léman, c'est un de ceux de la République où l'esprit facétieux est le plus comprimé, l'obéissance la plus entière et le crime le plus rare. Les délits qui ont été commis contre la sûreté générale ont été immédiatement réprimés et les criminels jugés par un Jury impartial ont été envoyés au supplice ", in Sismondi (1971, p. 166).

7. Naville (1790).

8. Massé ([s.d.], pp. 3-4).

9. Jean-Élisée Massé (1791-1870) a été président de la Cour de justice de Genève de 1842 à 1862. Recensant la totalité des 34 affaires criminelles dont l'issue fut fatale aux condamnés (nous reviendrons ultérieurement sur ces chiffres), le Relevé statistique représente à notre connaissance l'unique observation qui ait été faite de l'activité des juridictions criminelles du département du Léman; si la date de rédaction du manuscrit demeure inconnue, il a selon toute vraisemblance été écrit entre 1864 et 1870.

10. Cougnard (1826, p. 4). François Cougnard a été avocat et membre du Conseil représentatif de la République de Genève.

11. Sellon (1826 a). Membre du Conseil représentatif de la République depuis son institution et fervent abolitionniste, le magistrat genevois n'a eu de cesse, dès 1816, de proposer au Conseil d'État de présenter un projet de loi au Conseil souverain, dont l'effet serait d'abolir la peine de 
mort dans le code pénal qui doit régir la République et canton de Genève. Cependant, le Conseil d'État refusant systématiquement d'accéder à sa requête tant que la révision des lois criminelles ne sera pas à l'ordre du jour, Jean-Jacques de Sellon forme alors le vœu que «les hommes à talents qui pensent comme lui sur la peine de mort ne seront pas insensibles à la gloire de contribuer par leur éloquence à faire cesser des supplices qui ne sont plus en harmonie avec les mœurs d'un siècle qui réunit éminemment le sentiment religieux aux lumières qui [leur] ont été léguées par le siècle précédent ». Ibid. Précisons que le lauréat du concours est Charles Lucas, Lucas (1827); Petit (1990).

12. Ibid. Notons à ce propos que la construction d'une prison pénitentiaire est décrétée par le Conseil représentatif le 13 mars 1822.

13. À propos de la prison semi-panoptique de Genève, la meilleure contribution écrite reste Roth (1981). Voir également le film court-métrage de Caroline Cuénod : «Le panoptique, une prison modèle » (court-métrage documentaire, 2005, 27 min.), déposé à la médiathèque Uni-Bastions à Genève.

14. Cougnard (1826, pp. 5-6).

15. Sellon (1826 b,pp. 20-21). Dès 1800, le comte de Sellon prend pour demeure l'hôtel particulier familial sis au $n^{\circ} 2$ de la rue des Granges à Genève. Or, durant l'époque française, c'est précisément au pied des terrasses dudit hôtel, sur la place de la Porte de Neuve, qu'est dressé l'échafaud portant la guillotine. Élément de continuité avec l'Ancien Régime genevois : au XVIII ${ }^{\mathrm{e}}$ siècle, l'exécution publique de la peine par pendaison avait lieu au même endroit, Briegel, Porret (2005, p. 78).

16. Date de la première affaire jugée par le Tribunal criminel du département du Léman. Archives d'État de Genève (ci-après AEG), Archives du département du Léman (ci-après ADL) J 59.

17. AEG, ADL J 59, 60, 61.

18. Naville (1790) et Porret (1995). Ces chiffes ne prennent pas en compte les seize exécutions capitales prononcées par le Tribunal révolutionnaire pendant la Terreur de l'été 1794.

19. Si les juges rendent la loi en se conformant aux dispositions du Code pénal de la Constituante, force est de constater cependant que les régimes qui lui succèdent - Directoire, Consulat puis Empire - s'engagent dans une voie davantage répressive et liberticide. Aussi, les inquiétudes générées par les progrès du banditisme, de la désertion ou de la révolte engendrent-elles une réaction sécuritaire, qui tend à rejeter l'esprit du Code de 1791, au profit d'une voie autoritaire. La peine de mort est ainsi rétablie à l'encontre des voleurs avec armes et de leurs complices (loi du 26 floréal an V). La même sentence est prévue contre les individus s'étant rendus coupables d'effractions dans les maisons ou d'attaques à force ouverte sur les routes, chaque fois que les circonstances prouvent que ces actes ont pour motif le vol ou l'assassinat (loi du 29 nivôse an VI). Sommairement, la politique du Consulat puis de l'Empire se caractérise par un accaparement de la justice par l'État au détriment de la nation souveraine et de l'esprit démocratique de 1791 . L'idéal de perfectibilité humaine laisse désormais place à un souci grandissant de moralisation publique ainsi qu'à une aspiration manifeste à l'ordre et à la stabilité sociale, Schnapper (1991, 1999).

20. Briegel, Porret (2005).

21. En vigueur jusqu'en 1802, les tribunaux criminels deviennent des cours de justices criminelles, puis prennent le nom de cours d'assises en 1811.

22. Afin de mesurer la ventilation des peines prononcées par les juridictions criminelles du département du Léman, nous avons procédé à des regroupements. Les condamnations encourues par l'homo criminalis sont ainsi réparties en quatre types de peines: la mort, les travaux forcés (auxquels nous avons joint la peine des fers), l'emprisonnement criminel (qui comprend les différents modes de privation de liberté autres que les travaux forcés) et l'incarcération inférieure à deux ans. Dès lors, la répartition des peines prononcées par les juridictions criminelles lémaniques se présente comme suit : travaux forcés ( $34 \%)$, emprisonnement criminel 
(26\%), condamnations à moins de deux ans de prison (14\%) et enfin peine capitale $(10 \%)$, l'acquittement atteignant le taux de $16 \%$. Comparée aux chiffres obtenus dans le cadre d'une étude sur la pratique des juridictions criminelles de la Sambre-et-Meuse à l'époque française département « belge » également soumis à une modernisation judiciaire brutale - la proportion de condamnations à mort mesurée pour le Léman semble relativement élevée. En effet, le taux de condamnations à la peine capitale atteint $6 \%$ pour le tribunal criminel du département de Sambre-et-Meuse (1796-1810), puis $3 \%$ pour la cour d'assises (1811-1815). Aubusson de Cavarlay et al. (1999).

23. Ducpétiaux (1827, p. 98), voir aussi Ducpétiaux (1835). Pour l'anecdote, les exemplaires des ouvrages d'Édouard Ducpétiaux disponibles à la Bibliothèque de Genève résultent d'un don de l'auteur au comte de Sellon. Ce don est consécutif au Concours en faveur de la suppression absolue de la peine de mort organisé par Sellon en 1826, auquel Ducpétiaux a participé.

24. Nous avons opéré une construction de typologies d'infractions classiques, comprenant la distinction entre les crimes contre les biens (ce contentieux représente $57 \%$ des crimes commis durant la période), les crimes contre les individus ( $31 \%$ des crimes commis) et les atteintes à l'État (5\%); nous avons également considéré deux dernières catégories d'infractions faisant l'objet de rubriques distinctes : les atteintes à la morale (1\%) et les crimes de brigandage (6\%). En ce qui concerne les dispositions légales relatives à cette dernière catégorie, notons que la loi du 26 floréal an $\mathrm{V}$ établit la peine capitale pour toute personne convaincue du crime de brigandage, dès lors que la victime porte des traces de violence ou que les assaillants ont fait usage de leur arme à l'intérieur du domicile ou pour en forcer l'entrée. La loi se voit par ailleurs renforcée le 29 nivôse an VI: est dorénavant passible d'une condamnation à mort pour brigandage toute personne reconnue coupable de vol à main armée sur une route, au domicile d'un particulier, avec effraction, ou encore par escalade, Allen (2005, pp. 50-51); Schnapper (1999, p. 29).

25. Egmond (1993).

26. Pour une liste exhaustive des procès capitaux instruits à Genève durant l'époque française, voir Maugué (2006, Annexe 4).

27. Conformément à ce qu'indique L'Annuaire du département du Léman pour l'année 1811, les compétences de la Cour de justice criminelle spéciale sont les suivantes : «Cette Cour prononce, sans l'assistance de jurés, sur tous les crimes de faux, les crimes de fausse monnaie, d'incendie de granges, de contrebande à main armée et de rébellion à la force armée (voy. les lois des 23 floréal an 10, 13 floréal an 11, et 19 pluviôse an 13) », pp. 59-60. Cependant, il se trouve que, dans la pratique, les juridictions criminelles spéciales fonctionnent relativement peu à Genève. Elles traitent ainsi une cinquantaine d'affaires de juillet 1802 à mai 1807, soit en moyenne dix affaires par an, contre quarante pour la juridiction criminelle " ordinaire». L'activité des juridictions criminelles spéciales se restreint encore par la suite, puisque, d'octobre 1810 à mars 1813, seule une dizaine de jugements sont prononcés.

28. Parmi eux : deux infanticides, un matricide et deux crimes d'empoisonnement, les autres crimes étant presque essentiellement des assassinats.

29. Les quatre autres femmes sont jugées par contumace. Les crimes ayant engendré la condamnation suprême sont les suivants : deux infanticides, un assassinat, un incendie de grange et un cas de brigandage.

30. Outre 37 laboureurs/cultivateurs, nous dénombrons trois meuniers, deux cordonniers, deux cabaretiers, deux marchands, un domestique, un préposé aux douanes, un déserteur des armées françaises, un artiste vétérinaire, un horloger et un clerc de notaire (ces deux derniers ayant perpétré leur crime à Genève). Un seul individu se déclare sans profession, avant de se prétendre journalier, puis cabaretier; enfin, nous ignorons l'activité de six condamnés contumaces.

31. Frédéric Chauvaud indique à ce propos que le terme de cultivateur était «l'expression générique utilisée pour désigner les travailleurs de la terre, qu'ils soient propriétaire exploitant en faire-valoir, métayer ou domestique de ferme ", Chauvaud (1999, p. 31). 
32. Denys (2001).

33. Copie de lettres du Commissaire du Directoire exécutif,lettre $n^{\circ} 1746$, Genève, 9 floréal an VII. AEG, ADL A 40.

34. Massé ([s.d.], p. 5).

35. Condamné pour avoir assommé une jeune fille avec une hache avant de la brûler pour faire disparaître le cadavre. AEG, ADL J 59.

36. Pour l'ensemble de la discussion sur la guillotine, voir notamment Arasse (1987) et Martschukat (2000).

37. Arrêtés de l'administration centrale du département du Léman, Séancedu12ventôseanVII. AEG, ADL A 12. Cet épisode est également rapporté par Zurbruchen (1971). Dans cet article, l'ancien archiviste d'État confond le père et le fils Pasteur : l'exécuteur des Arrêts criminels pour le département du Léman se nomme bien Jean-François Pasteur et non Jean-Jacques Rodolphe Pasteur.

38. Registre des lettres écrites par le Commissaire du Directoire exécutif près l'administration centrale du département du Léman, lettre $n^{\circ} 1262$. AEG, ADL A 37.

39. Compte pour l'administration centrale du département du Léman, de Boiteux, entrepreneur de bâtiment. AEG, ADL, liasse CXCVII.

40. AEG, ADL, liasse CXCVII.

41. Cette somme s'avère considérable, puisqu'elle équivaut à 437 journées de travail pour un ouvrier genevois en 1799.

42. Compte pour l'administration centrale du département du Léman, de Boiteux, entrepreneur de bâtiment. AEG, ADL, liasse CXCVII.

43. AEG, ADL B 788.

44. Lettre du duc de Massa au préfet du département du Léman, Paris, 30 novembre 1811. AEG, ADL B 788.

45. À titre indicatif, en 1811, le salaire journalier d'un maître charpentier ou d'un maître maçon s'élève à 4 frs. Un ouvrier non nourri à la ville gagne pour sa part 2,25 frs par jour.

46. Exposé de la situation de la République, $1^{\mathrm{er}}$ frimaire an IX (22 novembre 1800). Cité par Schnapper (1991, p.Times17).

47. Voir Copie de lettre de l'administration centrale au commissaire du Directoire près l'administration municipale de Genève, 21 floréal an VII. AEG, ADL A 15.

48. Notamment, Code Pénal de 1791, Titre $1^{\mathrm{er}}$, Art. $4:$ «Quiconque aura été condamné à mort pour crime d'assassinat, d'incendie ou de poison, sera conduit au lieu de l'exécution, revêtu d'une chemise rouge. Le parricide aura la tête et le visage voilés d'une étoffe noire; il ne sera découvert qu'au moment de l'exécution ".

49. Jacques Le Fort (1757-1826) obtient le grade d'avocat en 1779, puis occupe la chaire de Droit à l'Université de Genève dès 1783. Membre du Conseil des CC en 1785, il est nommé à la grande cour de Justice en 1797. Trois ans plus tard, il accède à la charge de juge du tribunal d'appel siégeant à Lyon et devient président du Tribunal criminel du département du Léman, fonctions qu'il remplit jusqu'en 1804, date de sa nomination au Corps législatif. Il reprend son office auprès du Tribunal criminel en 1810, avant d'être nommé, une année plus tard, président du Tribunal de première instance de l'arrondissement de Genève.

50. Massé ([s.d.] pp. 7-8).

51. Règlement sur les frais d'exécution des Arrêts criminels, dressé en conformité de l'article 113 du Décret impérial du 18 juin 1811.

52. Delarue (1979).

53. Non datée, la soumission de l'exécuteur genevois Isaac Pasteur est consultable dans AEG, ADL B 788. L'abonnement lui sera finalement octroyé pour la somme de 300 francs (AEG, ADL B 788).

54. Lettre de Gélaz, charpentier, adressée au Préfet du département du Léman, Genève, 22 juin 1812. AEG, ADL B 788. 
55. Note manuscrite d'Antoine Didier, Genève, 17 mars 1813.AEG, ADL B 648K.

56. Note manuscrite d'Isaac Pasteur, Genève, 3 avril 1813. AEG,ADL B 648K. Selon la même source, l'exécuteur des Arrêts criminels reçoit un salaire identique pour s'être rendu à Bonneville le 30 décembre 1812, afin d'y afficher un extrait de jugement par contumace. Ce montant semble être le tarif de rigueur : l'exécuteur perçoit à nouveau 24 francs « pour la course " qui l'a conduit à Thonon où il a placardé l'extrait de jugement par contumace concernant le nommé André Dunant de Vacheresse, condamné à la peine de 10 années de réclusion.

57. Les réquisitoires des procureurs ne sont en effet pas répertoriés dans les Archives du département du Léman. Le seul que nous ayons pu consulter est relatif à l'affaire Rosset, Girod (1808).

58. Le Fort, J., Discours sur l'institution du Jury,prononcé aux promotions de l'Académie de Genève, le 15 juin 1801. AEG, Archives de famille Le Fort, $1^{\mathrm{e}}$ série, nouveau fonds, 3.

59. «Observations du Tribunal criminel du Léman sur le Projet de Code criminel », p. 1.

60. «Exhortation : relig. Prédication familière d'un prêtre pour inciter à la dévotion, à la pratique des devoirs moraux et religieux ", Rey (2005).

61. «Décret en forme d'instruction pour la procédure criminelle, 29 septembre - 21 octobre $1791 »$, Duvergier (1824-1826).

62. Le Fort, J., Résumés des causes criminelles, BGE, Ms suppl. 250, Exhortation des frères Chappaz.

63. Le Fort, J., Résumés des causes criminelles, BGE, Ms suppl. 248, Exhortation des époux Méry.

64. Le Fort, J., Résumés des causes criminelles, BGE,Ms suppl. 250, Exhortation d'André Trébilliod.

65. Le Fort, J., Résumés des causes criminelles, BGE,Ms suppl. 247, Exhortation de Leyat, Gavard, Montessuit et Douche.

66. Rousseaux et al. (1999).

67. Élément de continuité cependant, la charge d'exécuter les jugements criminels reste dévolue à la même famille; la «dynastie » Pasteur à Genève, comme les Sanson à Paris, conserve sa fonction.

68. Lettre du ministre de la Justice au président du Tribunal criminel du département du Léman, Paris, 21 messidor an 8. AN, BB-18-420.

69. Cet épisode est relaté par André Palluel-Guillard (1999, pp. 264-265).

70. Lettre du procureur général impérial près la Cour de justice criminelle du département du Léman à son Excellence le Grand Juge Ministre de la Justice, Genève, 12 septembre 1806.AN, BB-18-421.

71. Ibid.

\section{RÉSUMÉS}

S'inscrivant dans l'étude de la peine capitale à Genève durant l'époque moderne, cet article propose une analyse tant qualitative que quantitative de la pratique des juridictions criminelles du département du Léman. Il illustre en outre l'importance fondamentale que revêtent les quinze années d'annexion de Genève par la France, véritable lien entre l'arbitraire de la justice d'Ancien Régime et le libéralisme pénal et politique qui prévaut dans cette ville au XIX ${ }^{\mathrm{e}}$ siècle, un libéralisme qui doit beaucoup aux principes issus du nouveau paradigme pénal proposé par les constituants de 1791. Loin du regard péjoratif communément porté sur la " période française », 
l'annexion à la France est ici envisagée comme un facteur de modernisation aussi bien administratif que judiciaire. Ce nouvel éclairage a été rendu possible grâce au dépouillement, aussi bien à Genève qu'à Paris, d'un corpus de sources totalement inexploité à ce jour.

This article extends the study of death sentence in Geneva in modern time by providing an analysis, both quantitative and qualitative, of criminal jurisdiction practices in the Leman department. It is based on the study of hitherto unexplored sources in Geneva and Paris. It illustrates the fundamental importance of the 15- year period during which Geneva was annexed to France, and which constitutes a consistent link between the arbitrary nature of Ancien Régime justice and the penal and political liberalism prevailing in this city during the 19th century, a liberalism that owes a lot to the principles based on the new penal paradigm proposed by the members of the Constituant Assembly of 1791. Far from the stereotypes usually cast on "the French period», the annexation of Geneva by France is considered here as providing administrative as well as judicial modernization.

\section{AUTEUR}

\section{LUDOVIC MAUGUÉ}

Université de Genève, Faculté des Lettres, Département d'histoire générale, Rue Saint-Ours, 5

CH-1211 Genève 4, ludovic.maugue@lettres.unige.ch

Ludovic Maugué, licencié ès Lettres de l'Université de Genève en 2006, est actuellement assistant d'histoire moderne au sein du département d'histoire générale (Faculté des Lettres, Université de Genève). 